\title{
Comparative Study of the Effects of Topically Used Insulin and Simvastatin on Thermal Induced Burn in Diabetic Albino Rats
}

\author{
BASMA NABIL, M.Sc.; AHMED YASSIN, M.D.; AMANY ABDIN, M.D. and FLEUR FATHY, M.D. \\ The Department of Pharmacology, Faculty of Medicine, Tanta University, Tanta, Egypt
}

\begin{abstract}
Background: Diabetic wound healing is a major complication that may be delayed or impaired. This is resulting from abnormalities in inflammatory and oxidative stress responses, impaired growth factors production, angiogenic responses and collagen deposition.
\end{abstract}

Aim of the Work: The aim of this work was to investigate and compare possible effects of topical insulin and simvastatin on the tissue repair capacity, their anti-inflammatory and antioxidant effects.

Material and Methods: Sixty male Wister Albino rats were divided into 5 equal groups, group 1 normal burned received vehicle, group 2 diabetic burned received vehicle, group 3 diabetic burned received insulin in vehicle, group 4 diabetic burned received simvastatin in vehicle and group 5 diabetic burned received insulin in saline all applied topically. At certain end recording points $\left(3^{\mathrm{rd}}, 7^{\text {th }}, 14\right.$ th and 21 st days post burning) wound contraction percentage $\%$ was calculated and serum tumor necrosis factor- a (TNF-a), blood reduced glutathione and serum malonaldialdehyde (MDA) levels were estimated and dissected burn specimens were prepared for histopathological and immunohistochemical staining for VEGF and a-SMA.

Results: Insulin and simvastatin produced more than satisfactory results evidenced by significant improvement in the whole studied parameters.

Conclusion: Insulin and simvastatin have anti-inflammatory, antioxidant and angiogenic effects improving the healing properties. Although they both in vehicle exhibited similar effectiveness in regard the investigated parameters, they exhibited superiority over insulin in saline.

Key Words: Diabetic burn - Wound healing - Topical Insulin - Simvastatin

\section{Introduction}

DIABETES Mellitus (DM) is a metabolic disorder with hyperglycemia over a prolonged period. It is

Correspondence to: Dr. Basma Nabil, The Department of Pharmacology, Faculty of Medicine, Tanta University, Tanta, Egypt considered one of the most important health care problems due to its complications [1].

Impaired wound healing is a major complication of diabetes [2] and recent studies have reported that reduced lymphangiogenesis and angiogenesis during diabetic wound healing are thought to be a new therapeutic target [3] as in diabetic patients there is imbalance in the formation of blood vessels with abnormal pattern of angiogenesis that impairs the healing process and decreased angiogenesis with restriction of the entry of the inflammatory cells to the wound site and reduction of the amount of factors released by these cells [4]. It was found that FGF-2 and Platelet Derived Growth Factor (PDGF) have been reduced in diabetic experimental wounds. It was also proved that a high glucose which is topically administrated to wounds of nondiabetic rats inhibits the angiogenic process suggesting the direct role of high glucose in affecting angiogenesis in diabetes $[\mathbf{1 , 5}]$.

Wound healing is an interplay of many steps leading to restoration of the integrity of skin barrier, which includes inflammation, proliferation, cells migration and scar remodeling [6]. The impaired healing in diabetes is multifactorial including reduced angiogenesis and lymphangiogenesis [3], decreased fibroblast proliferation and migration, decreased inflammatory changes [7], tissue hypoxia and infection.

Insulin is a natural pancreatic polypeptide hypoglycemic hormone. It regulates energy metabolism, increases DNA replication ,protein synthesis, cellular proliferation, differentiation and growth. Recent studies showed that it plays a role in wound healing process $[\mathbf{8 , 9}]$

Simvastatin is a member of statins which are HMG-CoA reductase inhibitor used as cholesterol 
lowering agents. In addition to their cholesterol lowering action recent studies suggest their antiinflammatory, immunomodulatory, angiogenesis and anti-oxidative actions [10]. It reduces the infiltration of polymorph nuclear leukocytes and elevates VEGF secretion in injured arteries in a dose dependent manner [11], it prevents the diffusion of free radicals which are produced under the effect of the oxidative stress through its binding to phospholipids of lipoproteins [12].

\section{Material and Methods}

\section{Vehicle preparation:}

The study employed liquid crystalline gel like formulation containing a mixture of oleic acid, Tween 80, propylene glycol and distilled water [13]. Fresh formulations were prepared weekly and stored at $4^{\circ} \mathrm{C}$.

\section{Insulin:}

(Insulinagypt R $100 \mathrm{IU} / \mathrm{ml}$ vial) is a product of Medical Union Pharmaceuticals Company (MUP). It was applied to animals topically in two different preparations:

1- In the freshly prepared vehicle (to group 3 ) by replacing $1 \mathrm{ml}$ of distilled water with $100 \mathrm{IU}$ of insulin in vehicle.

2- In saline (to group 5) in a dose of $0.1 \mathrm{U}$ of regular insulin applied on the burnt area daily [14].

\section{Simvastatin:}

It is a pure powder from Hetero Labs Limited (Unit-1) INDIA purchased from October Pharma 6 October City-First Industrial Zone Egypt. It was applied topically to the burnt area dissolved in the freshly prepared vehicle by replacing 2 gram of distilled water with 2 gram of simvastatin, this produced liquid crystalline formula containing $2 \%$ $\mathrm{w} / \mathrm{w}$ of simvastatin [3].

\section{Streptozotocin (STZ):}

It is a pure powder purchased from Sigma Aldrich, used to induce diabetes in rats by dissolving the drug in 0.1 mole sodium citrate buffer $(\mathrm{pH}$ 4.) which was prepared as following:

1- Dissolve 2.101 gram of citric acid in $100 \mathrm{ml}$ distilled water.

2- Dissolve 2.941 gram of tri sodium citrate in 100 $\mathrm{ml}$ distilled water.

3- Mix $44.5 \mathrm{ml}$ of citric acid with $55.5 \mathrm{ml}$ of tri sodium citrate to gain citrate buffer $4.6 \mathrm{pH}$, then it was injected once i.p. in a dose of $60 \mathrm{mg} / \mathrm{kg}$ to induce type I diabetes $[15,16]$; the blood glu- cose level was checked 3 days later using a blood sample from the tail to detect diabetes.

\section{Animals groups and treatment protocols:}

This study was carried out using 60 male Wistar Albino rats weighing 150-200gm., obtained from Tanta University Animal House. Animals were acclimatized for 10 days before induction of diabetes as mentioned before, then each animal was anaesthetized using ether, the dorsal inter-scapular area was shaved using an electrical razor and a deep second degree burn was induced using a metallic solid aluminium bar $2 \mathrm{~cm}$ of diameter, previously heated in a boiling water [17]. The bar was maintained in direct contact to the shaved area for 15 seconds. The animals then were kept individually in plastic cages; they were fed standard food and water ad libitum through the whole period of the experiment.

Animals were divided into 5 equal groups (12 rats each) as following:

- Group 1: Non-diabetic burned received vehicle.

- Group 2: Diabetic burned group received vehicle.

- Group 3: Diabetic burned group treated with insulin in vehicle.

- Group 4: Diabetic burned group treated with simvastatin in vehicle.

- Group 5: Diabetic burned group treated with insulin in saline.

All drugs were applied topically daily immediately after induction of burn. At the recording end points 3 rd, ${ }^{7 \text { th }} 14$ th and 21 st days post-burn; 3 animals from each group were taken and the burned area was measured to calculate wound contraction [18] that expressed as the reduction in percentage (\%) of original wound size, by the following formula:

$\%$ Wound contraction on day $\mathrm{X}=$

$$
\frac{(\text { Area on day } 0-\text { Area on day X) }}{\text { Area on day } 0} \times 100
$$

These 3 rats were sacrificed and blood was collected by cardiac puncture from each animal and divided into two parts; one was stored and used for detection of reduced glutathione level and the other was centrifuged for obtaining serum and lipid peroxides malondialdehyde (MDA) and tumor necrosis factor- a (TNF- $(\mathrm{x})$ levels. A full thickness burned skin with a margin of normal skin from each rat was dissected and immediately fixed in 10\% formalin and processed for histopathological examination. 


\section{The immunohistochemical analysis:}

Staining was performed on formalin-fixed paraffin-embedded specimens for:

- Vascular Endothelial Growth Factor (VEGF) (VEGF ready to use for IHC, 1467-R7) this method is according to [19].

- Anti alpha smooth muscle actin ( $\alpha$-SMA) (asm1 ready to use for IHC, 113-R7), This method is according to Skalli, Ropraz [20]

\section{Statistical analysis:}

Results were analyzed statistically using software Statistical Package for the Social Science (SPSS) for windows, Version 23 (SPSS Inc., USA).

The level of significance was established as 5\% by One Way ANOVA followed by Tukey's post-Hoc test. Descriptive statistics were presented as Mean \pm Standard Error of mean.

This study was conducted in Pharmacology Department, Faculty of Medicine, Tanta University from October 2016-Febrauary 2017.

\section{Results}

All rats that have been injected with STZ showed symptoms of diabetes, the non-diabetic animals showed blood glucose level ranging (132$159 \mathrm{mg} / \mathrm{dl}$ ) while the diabetic animals showed (486$876 \mathrm{mg} / \mathrm{dl}$ ) through the whole period of the experiment. The treated groups either with insulin in vehicle, simvastatin in vehicle or insulin in saline showed significant increase in the wound contraction percentage with no significant difference on comparing the all treated groups to each other (Table 1). There was significant decrease in TNF$\alpha$ levels when compared to the untreated group, The simvastatin in vehicle treated group showed significant decrease in the $21{ }^{\mathrm{st}}$ day when compared to the other groups (Table 2). The all treated groups showed increase in blood reduced glutathione [21] levels, while on comparing the insulin in saline treated group to the other treated groups it showed significant decrease (Table 3). There was significant decrease in serum (MDA) levels, with no significant differences when comparing the all treated groups to each other (Table 4).

\section{Histopathological examination results:}

Similar histopathological patterns of the healing process were observed in non-diabetic burned group (group 1) and the all treated groups either with insulin in vehicle (group 3), simvastatin in vehicle (group 4) or insulin in saline (group 5). On the 3 rd post burn day group 2 showed total autolysis of both epidermis and dermis with dense inflammatory cells infiltrate Fig. (1A) while the other groups showed inflammatory response, hyperemia, necrosis with absence of the epithelial lining Fig. (1B). On the 7 th post burn day, thermal injury with intense inflammatory response was still observed in group 2 with complete destruction of epidermis and dermis Fig. (2A) while the other groups showed diffuse inflammatory response with angiogenesis and fibroblasts that induce collagen deposition (immature granulation tissue) Fig. (2B). on the 14th post burn day, group 1 showed moderate autolysis and immature granulation tissue with no surface epithelium Fig. (3A), while the other groups showed advanced healing process with reduction in the inflammatory reaction and well developed granulation tissue with epithelial surface lining Fig. (3B). on the 21 st day post burn, in group 1 there was no evidence of complete healing with tissue debris and thrombosed blood vessels Fig. (4A), while the other groups showed more advanced healing process with dense collagen deposition and complete epithelialization Fig. (4B).

\section{Immune histochemical study:}

The software (Image J) (National Institute of Health, Bethesda, Maryland, USA) [22] was used to measure the color intensity then data were analyzed by one way analysis of variance (ANOVA) test followed by Post Hoc Tukey's test.

Regarding VEGF the samples showed peak in the expression on the 14 th day, which was higher in the diabetic burned treated group with simvastatin in vehicle with significant increase on compared to the other treated groups (Table 5) Fig. (5). Regarding $\alpha$-SMA the samples showed a peak on the 7 th day, which was higher in the diabetic burned treated group with insulin in vehicle with significant increase on comparing to the other treated groups (Table 6) Fig. (6).

Table (1): Comparative statistics of wound contraction percentage among studied groups.

\begin{tabular}{|c|c|c|c|c|}
\hline & 3rd day & 7 th day & 14th day & 21 st day \\
\hline Group 1 & $37.5 \pm 2.5$ & $57.83 \pm 1.88$ & $87.25 \pm 0.63$ & $99.93 \pm 0.03$ \\
\hline Group 2 & $14.5 \pm 2.74 p 1^{* * *}$ & $37.33 \pm 2.67 p 1 * * *$ & $57.75 \pm 1.88 p 1^{* * *}$ & $94.25 \pm 0.29 p 1 * * *$ \\
\hline Group 3 & $38.92 \pm 1.34 p 2 * * *$ & $56.08 \pm 2.51 p 2 * * *$ & $82.75 \pm 2.43 p 2^{* * * *}$ & $99.63 \pm 0.07 p 2^{* * *}$ \\
\hline Group 4 & $34.75 \pm 1.38 p 2 * * *, p 3 \mathrm{NS}$ & $51.08 \pm 2.02 p 2 * *, p 3 \mathrm{NS}$ & $80 \pm 1.18 p 2 * * *, p 3 \mathrm{NS}$ & $99.38 \pm 0.13 p 2 * * *, p 3 \mathrm{NS}$ \\
\hline Group 5 & $26.33 \pm 2.83 p 2^{*}, p 3^{*}, p 4 \mathrm{NS}$ & $54.67 \pm 2.03 p 2^{* *}, p 3 \mathrm{NS}, p 4 \mathrm{NS}$ & $79.08 \pm 0.79 p 2 * * *, p 3 \mathrm{NS}, p 4 \mathrm{NS}$ & $98.8 \pm 0.38 p 2^{* * *}, p 3 \mathrm{NS}, p 4 \mathrm{NS}$ \\
\hline
\end{tabular}


Table (2): Comparative statistics of TNF- $\alpha$ (pg./ml) serum levels in studied groups.

\begin{tabular}{lllll}
\hline & 3rd day & 7 th day & 14 th day & 21 st day \\
\hline Group 1 & $0.85 \pm 0.03$ & $0.73 \pm 0.03$ & $0.76 \pm 0.02$ & $0.75 \pm 0.05$ \\
Group 2 & $1.98 \pm 0.03 p 1^{* * *}$ & $2.15 \pm 0.04 p 1^{* * *}$ & $3.25 \pm 0.25 p 1^{* * *}$ & $2.18 \pm 0.2 p 1^{* * *}$ \\
Group 3 & $1.15 \pm 0.09 p 2^{* * *}$ & $0.95 \pm 0.02 p 2^{* * *}$ & $0.74 \pm 0.18 p 2^{* * *}$ & $0.97 \pm 0.06 p 2^{* * *}$ \\
Group 4 & $1.04 \pm 0.06 p 2^{* * *}, p 3 \mathrm{NS}$ & $0.83 \pm 0.05 p 2^{* * *}, p 3 \mathrm{NS}$ & $1.04 \pm 0.1 p 2^{* * *}, p 3 \mathrm{NS}$ & $0.33 \pm 0.1 p 2^{* * *}, p 3 \mathrm{NS}$ \\
Group 5 & $0.93 \pm 0.01 p 2^{* * *}, p 3 \mathrm{NS}, p 4 \mathrm{NS}$ & $0.96 \pm 0.06 p 2^{* * *}, p 3 \mathrm{NS}, p 4 \mathrm{NS}$ & $1.18 \pm 0.1 p 2^{* * *}, p 3 \mathrm{NS}, \mathrm{v} 4 \mathrm{NS}$ & $1.29 \pm 0.22 p 2^{* * *}, p 3 \mathrm{NS}, p 4^{* *}$ \\
\hline
\end{tabular}

\begin{tabular}{lll}
\hline Significant at $p$-value $(<0.05)$; values expressed as mean \pm 出EM. & N.S: Non-Significant. \\
$*: p<0.05$ & $* *: p<0.01$ &
\end{tabular}

Table (3): Comparative statistics of GSH blood levels (nmol/ml) in studied groups.

\begin{tabular}{lllll}
\hline & 3rd day & 7 th day & 14 th day & 21 st day \\
\hline Group 1 & $8.89 \pm 0.14$ & $8.06 \pm 0.16$ & $9.34 \pm 0.25$ & $9.3 \pm 0.52$ \\
Group 2 & $4.89 \pm 0.24 p 1^{* * *}$ & $4.16 \pm 0.62 p 1^{* *}$ & $5.98 \pm 0.34 p 1^{* *}$ & $5.16 \pm 0.81 p 1^{* *}$ \\
Group 3 & $10.54 \pm 0.62 p 2^{* * *}$ & $14.37 \pm 0.93 p 2^{* * *}$ & $14.67 \pm 0.66 p 2^{* * *}$ & $14.59 \pm 0.91 p 2^{* * *}$ \\
Group 4 & $13.17 \pm 0.55 p 2^{* * *}, p 3^{* *}$ & $17.98 \pm 0.75 p 2^{* * *}, p 3^{* *}$ & $15.96 \pm 0.53 p 2^{* * *}, p 3 \mathrm{NS}$ & $15.31 \pm 0.39 p 2^{* * *}, p 3 \mathrm{NS}$ \\
Group 5 & $9.04 \pm 0.28 p 2^{* * *}, p 3 \mathrm{NS}, p 4^{* * *}$ & $9.83 \pm 0.3 p 2^{* * *}, p 3^{* *}, p 4^{* * *}$ & $9.73 \pm 0.25 p 2^{* *}, p 3^{* * *}, p 4^{* * *}$ & $10.8 \pm 0.37 p 2^{* * *}, p 3^{* *}, p 4^{* *}$ \\
\hline
\end{tabular}

Significant at $p$-value $(<0.05)$; values expressed as mean \pm \pm SEM.

$*: p<0.05 . \quad$ **: $p<0.01$. ${ }_{* * *:} p<0.001$.

N.S: Non-Significant.

Table (4): Comparative statistics of MDA serum levels ( $\mathrm{nmol} / \mathrm{ml})$ in studied groups.

\begin{tabular}{lllll}
\hline & 3rd day & 7 th day & 14 th day & 21 st day \\
\hline Group 1 & $6.44 \pm 0.25$ & $6.06 \pm 0.44$ & $4.42 \pm 0.55$ & $5.25 \pm 0.35$ \\
Group 2 & $9.13 \pm 0.36 p 1^{* * *}$ & $8.34 \pm 0.49 p 1^{* *}$ & $7.08 \pm 0.2 p 1^{* * *}$ & $7.21 \pm 0.22 p 1^{* *}$ \\
Group 3 & $8.16 \pm 0.53 p 2 \mathrm{NS}$ & $6.32 \pm 0.12 p 2^{*}$ & $4.59 \pm 0.31 p 2^{* * *}$ & $3.64 \pm 0.21 p 2^{* * *}$ \\
Group 4 & $8.3 \pm 0.25 p 2 \mathrm{NS}, p 3 \mathrm{NS}$ & $5.76 \pm 0.26 p 2^{* *}, p 3 \mathrm{NS}$ & $3.73 \pm 0.15 p 2^{* * *}, p 3 \mathrm{NS}$ & $3.39 \pm 0.21 p 2^{* * *}, p 3 \mathrm{NS}$ \\
Group 5 & $8.92 \pm 0.37 p 2 \mathrm{NS}, \mathrm{v} 3 \mathrm{NS}, p 4 \mathrm{NS}$ & $6.36 \pm 0.45 p 2^{*}, p 3 \mathrm{NS}, p 4 \mathrm{NS}$ & $4.85 \pm 0.36 p 2^{* *}, p 3 \mathrm{NS}, p 4 \mathrm{NS}$ & $4.12 \pm 0.13 p 2^{* * *}, p 3 \mathrm{NS}, p 6 \mathrm{NS}$ \\
\hline
\end{tabular}

Significant at $p$-value $(<0.05)$; values expressed as mean \pm SEM.

$*: p<0.05 . \quad$ * $*$ : $p<0.01$. $\quad$ **: $p<0.001$.

N.S: Non-Significant.

Table (5): Comparative statistics of the color intensity of VEGF in different studied groups.

\begin{tabular}{|c|c|c|c|c|}
\hline & 3rd day & 7 th day & 14th day & 21 st day \\
\hline Group 1 & $3.66 \pm 0.14$ & $5.53 \pm 0.03$ & $9 \pm 0.11$ & $5 \pm 0.11$ \\
\hline Group 2 & $2.28 \pm 0.05 p 1 * * *$ & $4.57 \pm 0.34 p 1 * *$ & $7.47 \pm 0.11 p 1^{* * *}$ & $4.34 \pm 0.06 p 1^{* * *}$ \\
\hline Group 3 & $5.09 \pm 0.13 p 2 * * *$ & $7.51 \pm 0.09 p 2^{* * *}$ & $13.04 \pm 0.07 p 2 * * *$ & $6.04 \pm 0.07 p 2 * * *$ \\
\hline Group 4 & $5.30 \pm 0.09 p 2^{* * *}, p 3 \mathrm{NS}$ & $7.88 \pm 0.07 p 2 * * *, p 3 \mathrm{NS}$ & $14.03 \pm 0.09 p 2^{* * *}, p 3^{* * *}$ & $8.03 \pm 0.09 p 2^{* * *}, p 3 * * *$ \\
\hline Group 5 & $4.98 \pm 0.07 p 2^{* * *}, p 3 \mathrm{NS}, p 4 \mathrm{NS}$ & $7.36 \pm 0.09 p 2^{* * *}, p 3 \mathrm{NS}, p 4 \mathrm{NS}$ & $12.8 \pm 0.13 p 2 * * *, p 3 \mathrm{NS}, p 4 * * *$ & $5.99 \pm 0.09 p 2^{* * *}, p 3 \mathrm{NS}, p 4^{* * * *}$ \\
\hline
\end{tabular}

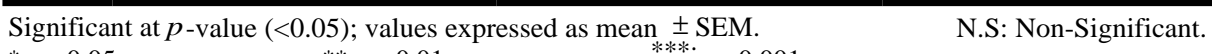

$*: p<0.05 . \quad$ **: $p<0.01$. $* * *: p<0.001$.

Table (6): Comparative statistics of the color intensity of $\alpha$-SMA in different studied group.

\begin{tabular}{lllll}
\hline & 3 rd day & 7 th day & 14th day & 21 st day \\
\hline Group 1 & $3.61 \pm 0.04$ & $14.78 \pm 0.14$ & $3.85 \pm 0.06$ & $2.22 \pm 0.04$ \\
Group 2 & $2.33 \pm 0.13 p 1^{* * *}$ & $8.33 \pm 0.19 p 1^{* * *}$ & $3.32 \pm 0.1 p 1^{* *}$ & $2.16 \pm 0.03 p 1 \mathrm{NS}$ \\
Group 3 & $4.82 \pm 0.5 p 2^{* * *}$ & $17.35 \pm 0.55 p 2^{* * *}$ & $6.78 \pm 0.09 p 2^{* * *}$ & $2.69 \pm 0.08 p 2^{* * *}$ \\
Group 4 & $4.67 \pm 0.15 p 2^{* * *}, p 3 \mathrm{NS}$ & $14.56 \pm 0.13 p 2^{* * *}, p 3^{* * *}$ & $5.24 \pm 0.09 p 2^{* * *}, p 3^{* * *}$ & $2.31 \pm 0.06 p 2 \mathrm{NS}, p 3^{* *}$ \\
Group 5 & $4.88 \pm 0.12 p 2^{* * *}, p 3 \mathrm{NS}, p 4 \mathrm{NS}$ & $16.05 \pm 0.12 p 2^{* * *}, p 3^{*}, p 4^{* * *}$ & $5.36 \pm 0.06 p 2^{* * *}, p 3^{* * *}, p 4 \mathrm{NS}$ & $2.45 \pm 0.06 p 2^{* *}, p 3 \mathrm{NS}, p 4^{*}$ \\
\hline
\end{tabular}

\begin{tabular}{lll}
\hline Significant at $p$-value $(<0.05)$; values expressed as mean $\underset{* *}{ \pm}$ SEM. & N.S: Non-Significant. \\
$*: p<0.05$ & **: $p<0.01$ &
\end{tabular} 

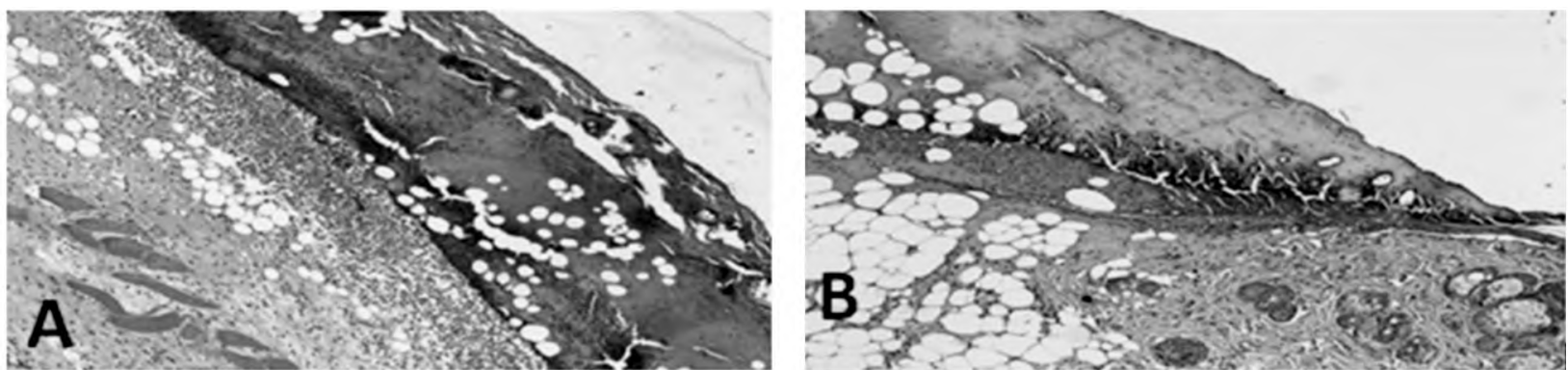

Fig. (1): (A) Deep inflammatory infiltrate, (B) Deep coagulative necrosis and inflammatory infiltrate.
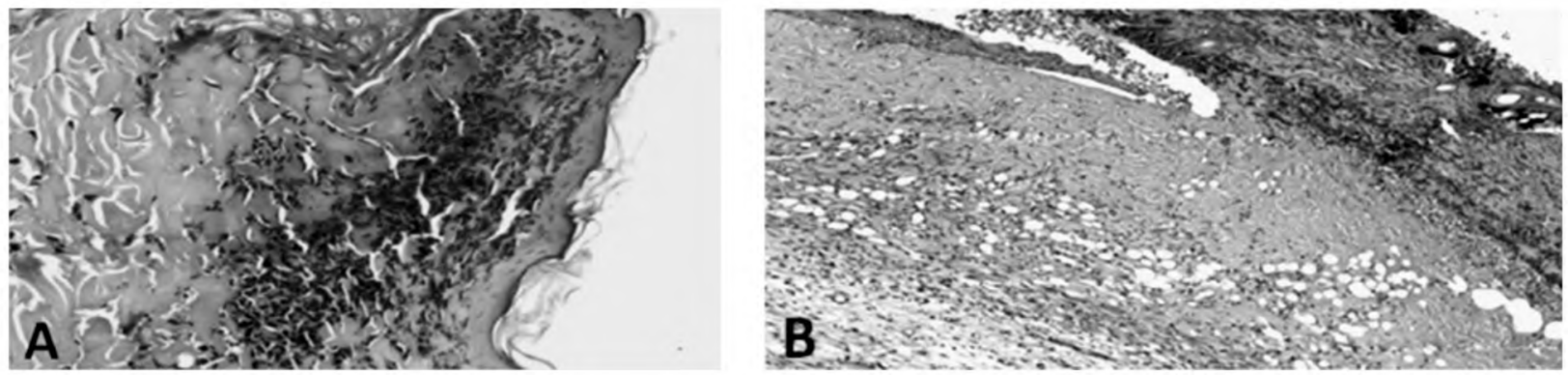

Fig. (2): (A) Intense inflammatory infiltrate, (B) Moderate inflammatory infiltrate, cogulative necrosis and crust.
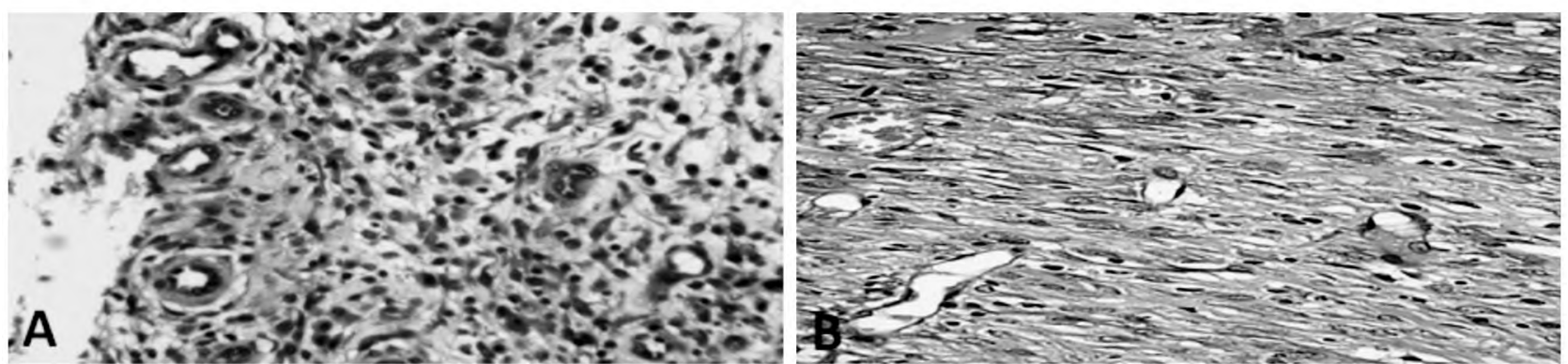

Fig. (3): (A) No epithelium with surface granulation tissue, (B) Developed granulation tissue (fibroblasts and blood capillaries).
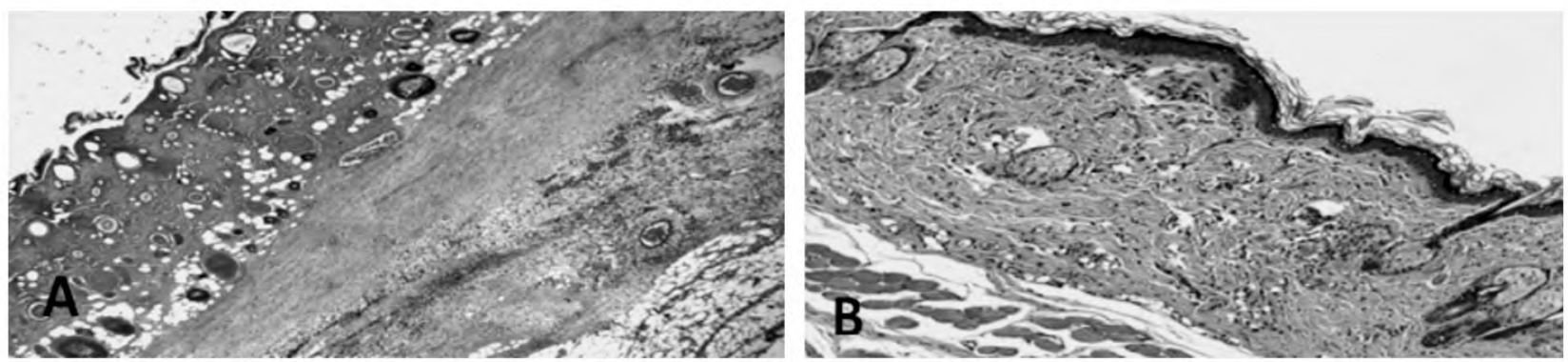

Fig. (4): (A) No evidence of complete healing and dilated thrombosed vessels, (B) Completely healed skin with minimal inflammatory cells.

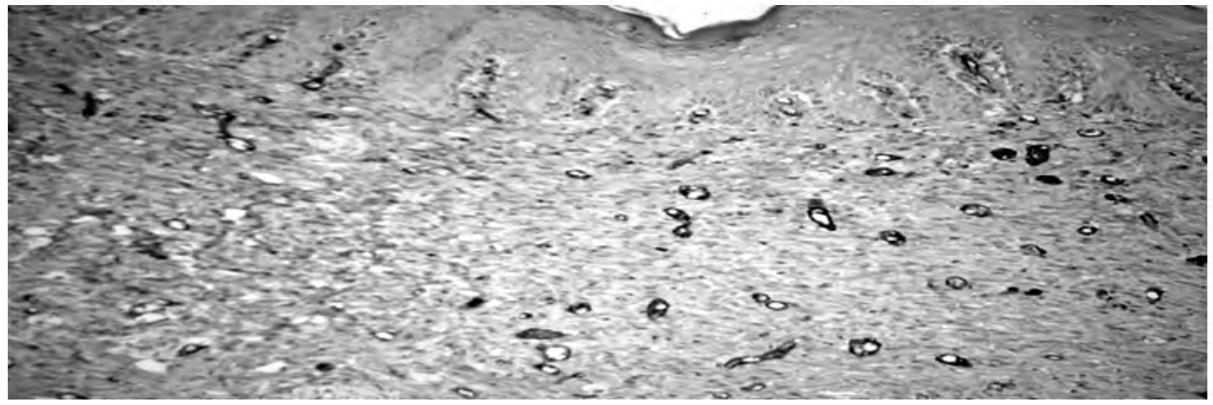

Fig. (5): IHC staining of CEGF showing newly formed blood vessels. 


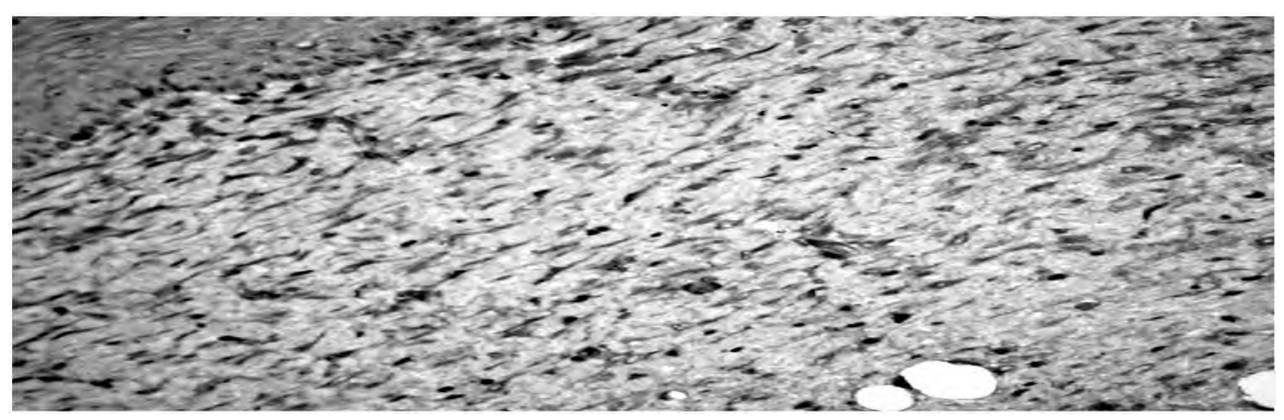

Fig. (6): IHC staining of $\alpha$-SMA showing fibroblasts.

\section{Discussion}

Diabetes is known to impair the healing process by affecting the inflammatory response, blood supply and fibroblast proliferation [23]. Defects in the inflammatory phase affect the subsequent process of fibroblast and collagen synthesis [24].

The microemulsion vehicle was used as a carrier improving the transdermal passage of tested drugs as El-Maghraby [13] has suggested that it has high drug loading capacity and penetration enhancing effect increasing the fluidity of the subcutanes lipids increasing drug permeability.

In the present study the induced deep second degree burn in diabetic rats induced with STZ showed significant decrease in wound contraction percentage, significant increase in serum TNF- $\alpha$, significant decrease in blood GSH and significant increase in serum MDA levels. Also, marked histopathological changes and decreased detection of VEGF and $\alpha$-SMA.

The increased TNF- $\alpha$ level impairs fibroblast proliferation, which was proved by invivo inhibition of TNF- $\alpha$ in diabetic mice that increase the number of proliferating fibroblast [25]. The impairment of migration of fibroblasts and keratinocytes was proved to be affected by TNF- $\alpha$ [26] .

Recent studies revealed that Reactive Oxygen Species (ROS) are required as defense against invading organisms, and also as essential mediators of intracellular signaling of migration, proliferation and angiogenesis, however excess ROS leading to cell apoptosis [27].

Vascular Endothelial Growth Factor (VEGF) is an angiogenic growth factor that functions as endothelial cell mitogen, chemotactic agent and inducer of vascular permeability. It has unique effects on multiple components of the healing process including angiogenesis, epithelialization and collagen deposition [28]
Lerman, [29] have proved that dermal fibroblasts obtained from diabetic mice have abnormalities even when allowed to grow in an ex-vivo optimized environment, as they show diminished VEGF production as a result of blunted fibroblast response to injury with profound effects on diabetic wound healing.

$\alpha$-SMA is a major myofibroblasts differentiation marker that regulates the expression of collagen gene, myofibroblasts which express that protein are strongly active compared with retractable protomyofibroblasts [30].

Insulin in vehicle showed a significant increase in the wound contraction percentage, that was in accordance with the results of Lima, Caricilli [23] who reported that topical insulin shortening the time needed for complete epithelialization, increase myofibroblasts expression and collagen deposition and stimulates proliferation of microvascular endothelial cells and with Goren, Müller [31] who proved that TNF- $\alpha$ inhibits the action of insulin and the diabetes-impaired wound healing is related to the failure of resident cells to respond in a proper way to insulin stimulus. Bravi, Armiento [32] demonstrated that insulin decreases the intracellular oxidative stress by elevating GSH/GSSG ratio in the erythrocytes from diabetic patients, and Langston, Circu [33] demonstrated that insulin affects GCLc expression and GSH recovery during oxidative challenge.

The significant decrease of serum MDA was in accordance with the results of Dhall, Silva [34] who reported that the insulin induced decrease in MDA levels indicates decrease in the oxidative stress that has a powerful consequences on the healing process. AbdelKader, Osman [35] have proved in their studies that insulin increases the expression and activation of AKT at the wound site as compared to intact skin which is important for VEGF release through a post-transcriptional mechanism which is important for angiogenesis. 
The significant increase of $\alpha$-SMA in wound area is in agreement with that of Tecilazich, Kafanas [36] who showed that diabetic patients treated with insulin suffer from thick skin as a result of excessive accumulation of abnormal collagen fibers that become resistant to be degraded by collagenase.

In the present study, simvastatin in vehicle showed a significant increase in the wound contraction percentage, these results are in agreement with Rego, et al. [37] who found that topical application of simvastatin on open diabetic wound, accelerates the healing process through the enhancement of angiogenesis and lymphangiogenesis; it also has a protective effects against infection due to its antibacterial action.

Regarding the serum levels of TNF- $\alpha$, simvastatin in vehicle showed significant decrease, these results are in agreement with Stojadinovic, Lebrun [11] and Farsaei, et al. [38] who reported the antiinflammatory effects of simvastatin are due to the inhibition of Th1-type chemokine receptors on $\mathrm{T}$ cells, inhibition of trans-endothelial migration of leukocytes and inhibition in the production of CRP and pro inflammatory cytokines (IL-6 and TNF$\alpha)$ and stimulating the production of antiinflammatory cytokine (IL-10).

Regarding to the oxidative stress, simvastatin in vehicle showed a significant increase in blood GSH levels, and these results were in harmony with Dalcico, et al. [39] who showed that simvastatin improved the gingival oxidative stress in experimentally induced periodontitis by re-establishing GSH levels and McFarlane, Muniyappa [40] who proved that all statins inhibit the uptake and generation of oxidized-LDL, attenuate vascular and endothelial superoxide anion formation.

It also showed a significant decrease in serum MDA levels, this was in accordance with the result of Jowkar and Namazi [41] who proved that it inhibits the activity of oxidant enzymes as reduced nicotinamide adenine dinucleotide phosphate oxidase and myeloperoxidase and up-regulates the activity of antioxidant enzymes such as catalase.

Simvastatin in vehicle showed a significant increase in expression of VEGF, these results were in harmony with that of Nishimoto et al. [42] who proved that simvastatin stimulates VEGF expression by HIF- $1 \alpha$ up-regulation and RhoA downregulation in endothelial cells and Bitto, et al. [43] who showed that simvastatin improves the altered pattern of VEGF production and secretion in mutant diabetic mice.
It also showed a significant increase in $\alpha$-SMA, These results were in controversy with Bagnato, et al. [44] who suggested that simvastatin administration inhibited myofibroblasts differentiation thus preventing the development of cutaneous and pulmonary fibrosis in systemic sclerosis model.

It was found that the inhibitory effect of simvastatin on TGF- $\beta$ 1-induced expression of $\alpha$-SMA was dose dependent. Concentrations of $10 \mathrm{Me}$ inhibit the $\alpha$-SMA production in keloid fibroblasts without affecting cell viability. Concentrations of 0.1-10 Mere reported to be within physiological relevant levels of the drug [45].

As a conclusion, insulin and simvastatin have anti-inflammatory, antioxidant and angiogenic effects improving the healing properties and could be recommended in the topical treatment of diabetic wounds. Although the treatment with insulin in vehicle exhibited similar effectiveness in regard the investigated parameters with simvastatin in vehicle, they exhibited superiority over insulin in saline denoting that such vehicle could provide good contact and penetration properties.

\section{References}

1- TELLECHEA A., et al.: Inflammatory and angiogenic abnormalities in diabetic wound healing: Role of neuropeptides and therapeutic perspectives. The Open Circulation and Vascular Journal, 3: p. 43-55, 2010.

2- BREM H. and TOMIC-CANIC M.: Cellular and molecular basis of wound healing in diabetes. Journal of Clinical Investigation, 117 (5): p. 1219, 2007.

3- ASAI J., et al.: Topical simvastatin accelerates wound healing in diabetes by enhancing angiogenesis and lymphangiogenesis. The American journal of pathology, 181 (6): p. 2217-24, 2012.

4- DAVIDSON J.M. and DIPIETRO L.: The wound-healing process, in The Diabetic Foot, Springer. p. 59-82, 2006.

5- DETMAR M., et al.: Hypoxia regulates the expression of vascular permeability factor/vascular endothelial growth factor (VPF/VEGF) and its receptors in human skin. Journal of Investigative Dermatology, 108 (3): p. 263-8, 1997.

6- DURGAPRASAD S., et al.: Effect of a topical curcumin preparation (BIOCURCUMAX) on burn wound healing in rats. Journal of Pharmaceutical and Biomedical Sciences (JPBMS), 8 (08), 2011.

7- BAIRY K., ABHINAV R. and SATYAM S.M.: Evaluation Of Burn Wound Healing Activity of Topical Regular Insulin In Non-Diabetic And Streptozocin-Induced Diabetic Rats. International Journal of Pharmacy and Pharmaceutical Sciences, 6 (8), 2014.

8- GOENKA G., et al.: Role of topical use of insulin in healing of chronic ulcer. Medical Journal of Dr. DY Patil University, 7 (5): p. 579, 2014. 
9- EMANUELLI T., BURGEIRO A. and CARVALHO E.: Effects of insulin on the skin: Possible healing benefits for diabetic foot ulcers. Archives of dermatological research, 308 (10): p. 677-94, 2016.

10- EL-AZAB M.F., HAZEM R.M. and MOUSTAFA Y.M. Role of simvastatin and/or antioxidant vitamins in therapeutic angiogenesis in experimental diabetic hindlimb ischemia: Effects on capillary density, angiogenesis markers, and oxidative stress. European Journal of Pharmacology, 690 (1): p. 31-41, 2012.

11-STOJADINOVIC O., et al.: Statins as potential therapeutic agents for healing disorders, 2010.

12- STOLL L.L., et al.: Antioxidant effects of statins. Drugs of Today, 40 (12): p. 975-90, 2004.

13- EL MAGHRABY G.M.: Self-microemulsifying and microemulsion systems for transdermal delivery of indomethacin: Effect of phase transition. Colloids and Surfaces B: Biointerfaces, 75 (2): p. 595-600, 2010.

14-BAIRY K., ABHINAV R. and SATYAM S.M.: Evaluation Of Burn Wound Healing Activity of Topical Regular Insulin In Non-Diabetic and Streptozocin-Induced Diabetic Rats. International Journal of Pharmacy and Pharmaceutical Sciences, 6(8): p. 127-30, 2014.

15- REES D. and ALCOLADO J.: Animal models of diabetes mellitus. Diabetic Medicine, 22 (4): p. 359-70, 2005.

16- ETUK E.: Animals models for studying diabetes mellitus. Agric. Biol. J.N. Am., 1 (2): p. 130-4, 2010.

17- PEREIRA T., et al.: Development of animal model for studying deep second-degree thermal burns. Bio. Med. Research International, 2012. 2012.

18- SHETTY N. and AMUTHAN A.: Evaluation of wound healing activity of ethanolic extract of Lantana camara in streptozotocin induced diabetic rats. International Journal of Pharmacy and Pharmaceutical Sciences, 6 (1): p. 631-3, 2014.

19- O'BYRNE K., et al.: Vascular endothelial growth factor, platelet-derived endothelial cell growth factor and angiogenesis in non-small-cell lung cancer. British Journal of cancer, 82 (8): p. 1427, 2000.

20- SKALLI O., et al.: A monoclonal antibody against alphasmooth muscle actin: A new probe for smooth muscle differentiation. The Journal of cell biology, 103 (6): p. 2787-96, 1986.

21- DING J., et al.: Synergistic effect of Vitamin D and low concentration of transforming growth factor beta 1 , a potential role in dermal wound healing. Burns, 42 (6): p. 1277-86, 2016

22- SCHNEIDER C.A., RASBAND W.S. and ELICEIRI K.W.: NIH Image to Image J. 25 years of image analysis. Nature Methods, 9 (7): p. 671-5, 2012.

23- LIMA M.H., et al.: Topical insulin accelerates wound healing in diabetes by enhancing the AKT and ERK pathways: A double-blind placebo-controlled clinical trial. PloS one, 7 (5): p. e36974, 2012.

24- EBAID H., et al.: Camel milk peptide improves wound healing in diabetic rats by orchestrating the redox status and immune response. Lipids in health and disease, 14 (1): p. 132, 2015.

25- SIQUEIRA M.F., et al.: Impaired wound healing in mouse models of diabetes is mediated by TNF- a dysregulation and associated with enhanced activation of forkhead box O1 (FOXO1). Diabetologia, 53 (2): p. 378-88, 2010.

26- XU F., ZHANG C. and GRAVES D.T.: Abnormal cell responses and role of TNF-in impaired diabetic wound healing. Bio. Med. Research International, 2013. 2013.

27- KURAHASHI T. and FUJII J.: Roles of antioxidative enzymes in wound healing. Journal of Developmental Biology, 3 (2): p. 57-70, 2015.

28- BAO P., et al.: The role of vascular endothelial growth factor in wound healing. Journal of Surgical Research, 153 (2): p. 347-58, 2009.

29- LERMAN O.Z., et al.: Cellular dysfunction in the diabetic fibroblast: impairment in migration, vascular endothelial growth factor production, and response to hypoxia. The American Journal of Pathology, 162 (1): p. 303-12, 2003

30- BOGATKEVICH G.S., et al.: Contractile activity and smooth muscle a-actin organization in thrombin-induced human lung myofibroblasts. American Journal of Physiology-Lung Cellular and Molecular Physiology, 285 (2): p. L334-L43, 2003.

31- GOREN I., et al.: Severely impaired insulin signaling in chronic wounds of diabetic ob/ob mice: A potential role of tumor necrosis factor- a. The American Journal of Pathology, 168 (3): p. 765-77, 2006.

32- BRAVI M.C., et al.: Insulin decreases intracellular oxidative stress in patients with type 2 diabetes mellitus. Metabolism, 55 (5): p. 691-5, 2006.

33- LANGSTON W., CIRCU M.L. and AW T.Y.: Insulin stimulation of Y-glutamylcysteine ligase catalytic subunit expression increases endothelial GSH during oxidative stress: influence of low glucose. Free Radical Biology and Medicine, 45 (11): p. 1591-9, 2008.

34- DHALL S., et al.: Release of insulin from PLGA-alginate dressing stimulates regenerative healing of burn wounds in rats. Clinical Science, 129 (12): p. 1115-29, 2015.

35- ABDELKADER D., et al.: The Role Of Insulin In Wound Healing Process: Mechanism Of Action And Pharmaceutical Applications. Journal of Analytical \& Pharmaceutical Research, 2 (1), 2016.

36- TECILAZICH F., KAFANAS A. and VEVES A.: Cutaneous alterations in diabetes mellitus. Wounds: A compendium of clinical research and practice, 23 (7): p. 192-203, 2011.

37- REGO A.C., et al.: Simvastatin improves the healing of infected skin wounds of rats. Acta Cirúrgica Brasileira, 22: p. 57-63, 2007.

38- FARSAEI S., KHALILI H. and FARBOUD E.S.: Potential role of statins on wound healing: Review of the literature. International Wound Journal, 9 (3): p. 238-47, 2012.

39- DALCICO R., et al.: Protective mechanisms of simvastatin in experimental periodontal disease. Journal of Periodontology, 84 (8): p. 1145-57, 2013. 
40- McFARLANE S., et al.: Pleiotropic effects of statins: Lipid reduction and beyond. The Journal of Clinical Endocrinology \& Metabolism, 87 (4): p. 1451-8, 2002.

41- JOWKAR F. and NAMAZI M.R.: Statins in dermatology. International Journal of Dermatology, 49 (11): p. 1235 43, 2010.

42- NISHIMOTO-HAZUKU A., et al.: Simvastatin stimulates vascular endothelial growth factor production by hypoxiainducible factor- $1 \alpha$ upregulation in endothelial cells. Journal of Cardiovascular Pharmacology, 51 (3): p. 267 73, 2008.
43- BITTO A., et al.: Simvastatin enhances VEGF production and ameliorates impaired wound healing in experimental diabetes. Pharmacological Research, 57 (2): p. 159-69, 2008.

44- BAGNATO G., et al.: Simvastatin attenuates the development of pulmonary and cutaneous fibrosis in a murine model of systemic sclerosis. Rheumatology, 52 (8): p. 1377-86, 2013.

45- MUN J.H., et al.: Simvastatin inhibits transforming growth factor- $\beta 1$-induced expression of type I collagen, CTGF, and a-SMA in keloid fibroblasts. Wound Repair and Regeneration, 22 (1): p. 125-33, 2014.

\section{دراسة مقارنة عن تآثيرات الإستخدام الموضعى الوائي

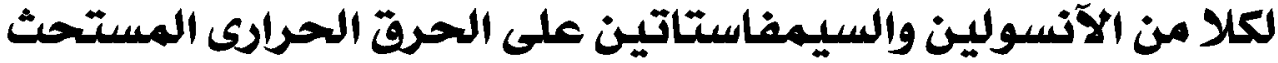

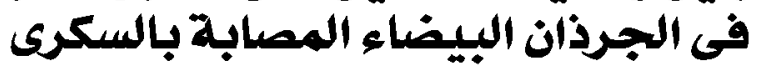

إلتئام الجرح هي عملية معقدة تتضمن إستجابات مختلفة للعديد من الخلايا لتكوين وتتظيم هراحل الإلتئام من تكوين نسيج إلتهابى وتكاثر

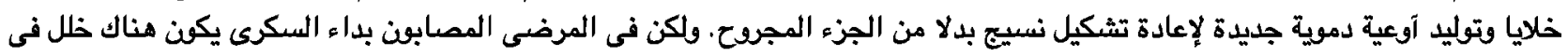

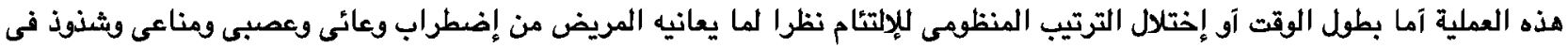

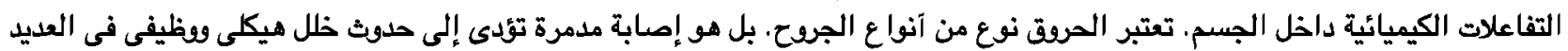

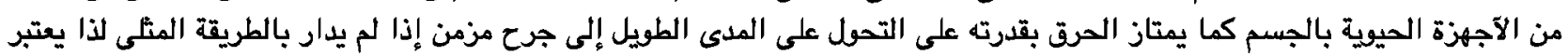

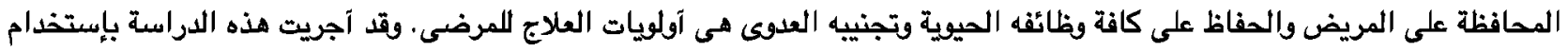
الآنسولين والسيمفاستاتين موضعيا على حرق حرارى مستحث فى جرذان بيضاء مصابة بالسكرى لتقيسم ومقارنة تآثيراتهم المختلفة والقدرة

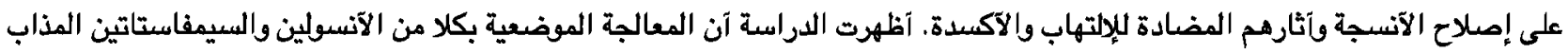

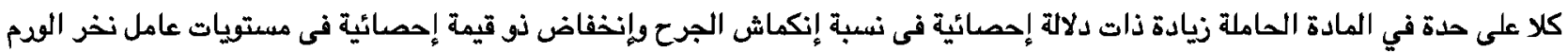

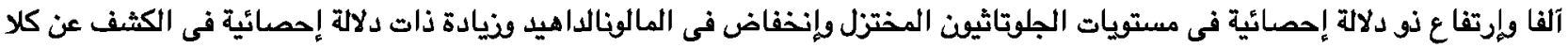

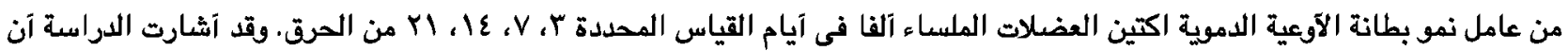

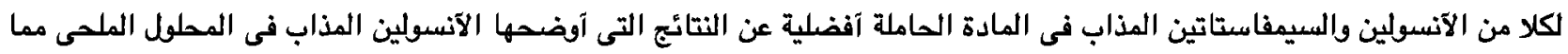

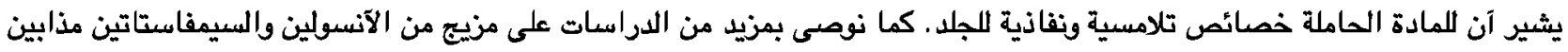

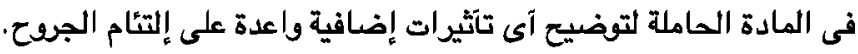

